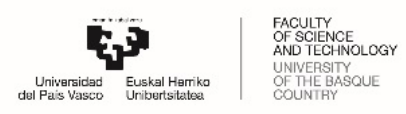

\title{
CBL
}

\section{Sustainability Transformation in Teaching Organic Chemistry Laboratory at University of the Basque Country}

\author{
I. Montes $^{1 *}$, S. Arrasate ${ }^{1}$, E. Anakabe ${ }^{1}$, M. Merino ${ }^{2}$, U. Akesolo ${ }^{1}$, S. López ${ }^{3}$ \\ ${ }^{1}$ Organic Chemistry II, Faculty of Science and Technology, UPV/EHU, Barrio Sarriena s/n, 48940 Leioa, Bizkaia \\ ${ }^{2}$ Applied Mathematics and Statistics and Operational Research, Faculty of Science and Technology, UPV/EHU, Barrio Sarriena s/n, 48940 Leioa, Bizkaia
} ${ }^{3}$ Faculty of Science and Technology, UPV/EHU, Barrio Sarriena s/n, 48940 Leioa, Bizkaia

e-mail*: imontes009@ikasle.ehu.eus

\section{Introduction}

In order to deepen the problem of hazardous organic waste, we performed an exhaustive analysis of the waste generated in the teaching laboratories of the Organic Chemical II Department. Likewise, all the students involved in those practices have answered a questionnaire in order to know their prior knowledge in the subject and the awareness of the correct separate organic waste. The results have been analyzed with a Statistical Analysis Software making a cheminformatics model to be able to make the best decisions for the prevention, reduction and reuse of waste. This is a good way to promote the circular economy within the university, involving the different groups such as students or teachers.

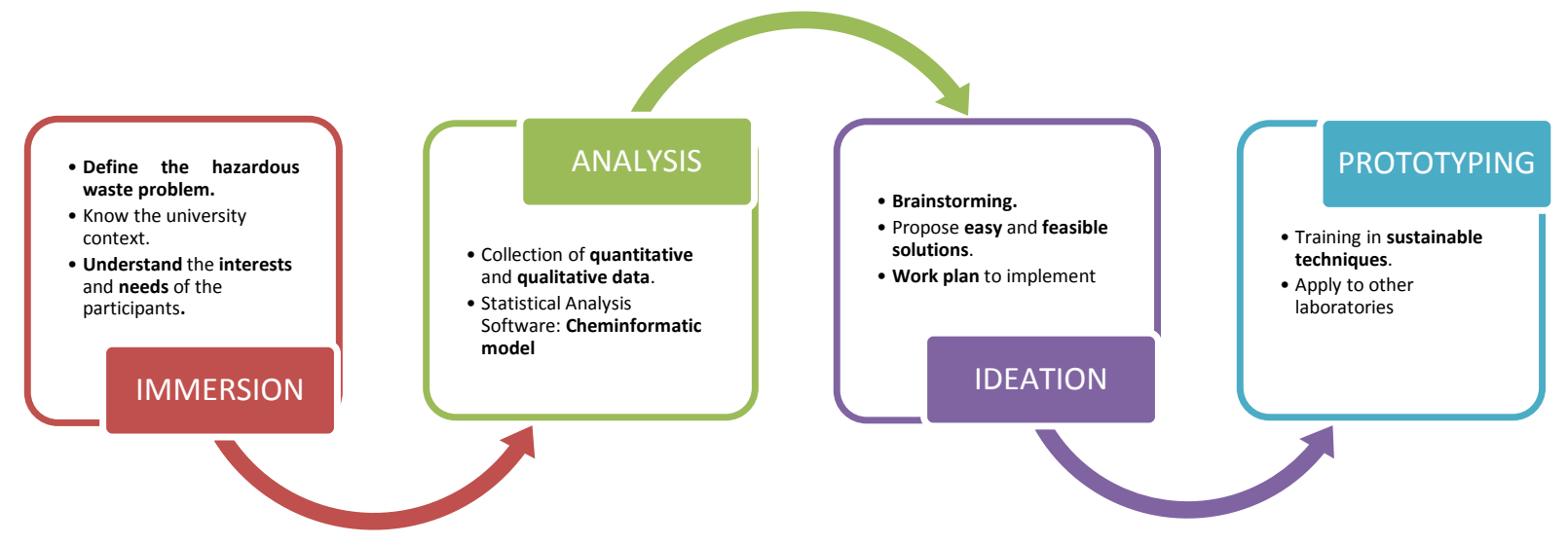

The production or transformation of any material for scientific and / or economic purposes generates products without commercial value, utility or benefit. These products are known as waste, and although many are inert or reused in other processes, the rest are waste. Wastes can be classified as hazardous, non-hazardous, active or passive and, depending on the classification, and can contaminate the environment [1]. That is why the correct management of them, especially the dangerous ones, is indispensable. 
All aspects related to the progressive increase of the quality of life that has been reached in today's society it is related with chemistry. The correct way to a sustainable future in the welfare state must necessarily involve chemistry [2]. Paul Anastas and John C. Warner already described some of those principles or guidelines in their 1998 book Green Chemistry: Theory and Practice.

The present study aims to analyse the development, management and implementation of sustainable practices within the waste management program of the university itself, and follows the lines outlined by the study Development of a Waste Management Program in Technical Chemistry Teaching [3] published on March 23, 2018

In addition, taking into account the results obtained in this study, laboratory practical procedures and techniques of the laboratories can be modified. Appropriate use of hazardous waste containers will also be encouraged, making labelling more understandable to students, preventing accidental spills in inappropriate containers, and fostering a more ecological and sustainable awareness

\section{Conclusions}

The conclusions of this analysis can be applied to other laboratories in different areas of the Faculty of Science and Technology and / or to research laboratories. After that, they can also be implemented in other campuses and centers of the University of the Basque Country. The ultimate goal would be to reduce the amount of hazardous waste generated in the organic teaching laboratories of the Faculty of Science and their directly related economic cost.

\section{References (mandatory)}

[1] Gerbase, A. E.; Coelho, F. S.; Machado, P. F. L.; Ferreira, V. F. Management of Chemical Waste in Institutions of Education and Research. Quim. Nova 2005, v.28 p.3.

[2] Lasagabaster Herrarte, Iñaki (coord.). La sostenibilidad desde la Universidad: una reflexión interdisciplinar. Sostenibilidad en química. Editorial service of the University of the Basque Country. 2013. p. 62-65.

[3] G. Ramm, Julia; L. Dorscheid, Gabryel; G. Passos, Camila; Sirtori, Carla Development of a Waste Management Program in Technical Chemistry Teaching. Journal of Chemical Education 2018, 95 (4), 570-576.

\section{Aknowledgements}

This investigation has been carried out with economical support of the Vice-Rector's Office of Innovation, Social Commitment and Cultural Action of the University of the Basque Country, from the funding assigned within the contract-program formalized with the Basque Government. 